\title{
Interactive comment on "Oceanic response to the consecutive Hurricanes Dorian and Humberto (2019) in the Sargasso Sea" by Dailé Avila-Alonso et al.
}

Jill Trepanier (Referee)

jtrepa3@lsu.edu

Received and published: 1 December 2020

This paper focuses on the oceanic responses to the passing of two hurricanes in 2019. It is well-written, topically relevant to the current literature, and showcases some interesting graphics. I have read through the previous reviewers' reports so I will add new information below and potentially reinforce some of the early reviews.

I agree that the introduction focuses more on climate change and TCs and less on upper ocean response. Please add literature and introductory comments on the expectation of upper ocean changes from the passing of hurricanes. An additional paragraph should suffice. Do not take out what you have - it is well written and supports the ideas.

Printer-friendly version

Discussion paper 
You need only add a little more. This will help the remaining parts of your paper pack more of an important "punch" if we are more aware of why it matters to be looking at NHESSD Chl-a.

Section 2.1. Please refer to Figure 1 as your "study area graphic", it will lead to your figure being moved up slightly which helps the reader identify the location.

Interactive

comment

Did you do any assessment of other conditions of the atmosphere in the "pre-storm" week of Dorian? Meaning, did it rain at all during that time? Rainfall from minor to severe thunderstorms can alter your SSTs in the region and, without mention of it, I'm not sure that other atmospheric events might be biasing your results. You mention TC Erin. Were there any other events? Please comment.

Paragraph including line 190: the way you worded the beginning of this paragraph is confusing. Please rephrase.

Great Figure 2. Really showcases what you are describing.

In paragraph with line 275, you bring it up yourself that the findings are similar with Ezer (2018) (or later, Foltz et al. 2015). So why is your study different? And, thus, why is it important that it is published? I think you need a stronger argument than you have presented here. Broader impacts related to your study can be helpful here.

I think your conclusion needs to be strengthened. While you provide a nice summary of what are interesting statistics, you need to relate it to a broader picture. Why does knowing this information help us in some way? Does it inform fisheries? Does it inform management practices? Why does it matter? (I believe it does, but you need to provide a stronger argument for it).

Interactive comment on Nat. Hazards Earth Syst. Sci. Discuss., https://doi.org/10.5194/nhess2020-296, 2020.

Printer-friendly version

Discussion paper 